\title{
ARTÍCULO
}

\section{Caracterización de la Paz en Colombia como escenario de construcción de nuevas pedagogías en ciencia y tecnología}

\author{
Rodríguez-Camargo, Christian*, Ochoa-Duarte, Alexei ${ }^{\circ}$ \\ * Corporación Universitaria Minuto de Dios, Departamento de Ingeniería Industrial, Centro de \\ Estudios Industriales y Logísticos para la Productividad (CEIL, MD), cdrodriguezc@unal.edu.co \\ - Universidad Nacional de Colombia, Departamento de Ingeniería de Sistemas e Industrial, \\ agochoad@unal.edu.co
}

En este artículo se realiza una aproximación teórica y conceptual a la caracterización de la construcción de Paz en Colombia como el escenario propicio para la generación de nuevas epistemologías científicas y tecnológicas, y con ello, la consolidación de nuevas pedagogías en este campo. Este acercamiento se realiza, en primer lugar, con un estudio sobre el origen del conflicto armado en Colombia. Se analiza cómo estas particularidades se ven reflejadas en el subsecuente desarrollo de las políticas de ciencia y tecnología. Paralelo a este análisis histórico, se da la discusión sobre la necesidad de una nueva estructura epistemológica que permita la generación de alternativas y estrategias pedagógicas. Posteriormente, se plantea que un inicio para ello es una simbiosis entre las energías renovables y alternativas, la agroecología y la etnobiología. Esta simbiosis se conceptualiza para servir de base a la propuesta central de este trabajo que consiste en estipular la coyuntura del pos-acuerdo, como escenario ideal para la creación de las mencionadas nuevas epistemologías y pedagogías en las que las tecnologías libres. Posibles extensiones y relevancias de los resultados son discutidas.

\section{Palabras clave:}

Pedagogía en CyT, Tecnologías Libres, Energías Renovables y Alternativas, Agroecología etnobiología, Acuerdos de Paz.

\section{INTRODUCCIÓN}

Orlando Fals Borda fue uno de los primeros pensadores latinoamericanos modernos en sentar grandes discusiones sobre la pertinencia del esquema epistemológico dominante de la ciencia en la 
generación de conocimiento científico y tecnológico, que respondiera a las necesidades del contexto latinoamericano (Ocampo López, 2009). Indicaba que para la generación de este conocimiento pertinente, la ciencia debería abandonar ciertas bases fundamentales del positivismo y abrirse a una construcción conjunta con las comunidades, comprendiendo que el proceso de investigación científica, es un proceso participativo y transformador, que tendría una mayor posibilidad de ser exitoso en el marco de establecer un diálogo entre los múltiples saberes coexistentes en un mismo espacio (Fals Borda, 1986). Otros autores latinoamericanos llegaron a la misma conclusión de que el esquema positivista estaba agotado para el contexto regional. Un ejemplo de ello es el intelectual cubano Fidel Martínez Álvarez, quien abre la discusión para el continente sobre Ciencia, Tecnología y Sociedad (CTS), con estudios sobre la concepción heredada de la ciencia (Martínez, s.f).

Este problema fue abordado también desde otras esferas de la actividad humana. En el caso económico tenemos a intelectuales mexicanos como Alejandro Nadal Egea (1977) y Víctor Urquidi (1962), quienes formularon políticas públicas a partir de la comprensión de este problema. En Brasil se tiene el ejemplo de María Concepción Tavares (Possas, 2001) que formula estrategias en clave de la educación; también del físico José Leite Lopes (1998) que lo hace desde el quehacer propio científico y político, y claro está, sin contar los grandes aportes a un nivel más general de Paulo Freire (1987), José Paulo Netto (2012), Mauro Luís Iasi (2007) y Theotônio dos Santos (2000) (siguiendo una línea lingüística desde Portugal también están los valiosos aportes de Boaventura de Sousa Santos, 2014). Mientras que en la Argentina, Aldo Ferrer (2003) establece relación entre las estructuras económicas latinoamericanas y la generación de conocimiento tecnológico; se han realizado también, a partir de revisiones críticas de la distinción tradicional de la ciencia, como producto y como proceso, recorridos sobre la filosofía de las ciencias que llevan a la discusión de pensar (y repensar) el lugar del pensamiento científico, y el nuestro, en el mundo actual (Palma, 2008; Lombardi, 2015); por otro lado, Esther Díaz de la Universidad de Lanús, enmarca las discusiones epistemológicas de la concepción heredada de la ciencia y la tecnología desde un enfoque ético, cultural, artístico y del poder (Díaz, 2010).

La decolonización del saber también fue discutida en Colombia por Arturo Escobar (1996; 2014) desde la cuestión del desarrollo y diálogo de saberes; y también se podría nombrar a Carlos Eduardo Maldonado (2016) desde la complejidad e interdisciplinareidad como eje de avance de la ciencia latinoamericana, entre otros. Sin embargo, esta discusión en el marco de la ciencia y tecnología, ha quedado un poco relegada en comparación con los avances que se han logrado en México, Cuba, Brasil, Uruguay y Argentina. Es por ello que este trabajo busca retomar estas discusiones y construcciones, trayéndolas al contexto actual Colombiano que brinda la firma de los Acuerdos de Paz de la Habana entre el gobierno nacional y la insurgencia de las FARC-EP. Debido a las diversas acciones que nuestros grupos de investigación ${ }^{1}$ han emprendido con las comunidades de campesinos, afros, indígenas y excombatientes afectadas por el conflicto armado, hemos encontrado, al igual que lo hicieron los pensadores mencionados y otros tantos, que el esquema positivista para la generación de conocimiento científico y tecnológico, no es el más apto para el contexto de la construcción de paz en Colombia.

1 Nuestros grupos son: Centro de Estudios Industriales y Logísticos para la Productividad (CEIL, MD); Grupo de Investigación en Tecnología e Innovación para el Desarrollo Comunitario (GITIDC); Centro de Alternativas para el Desarrollo (CEALDES); y Programa de Adquisición y Análisis de Señales (PAAS, UN). 
Este trabajo corresponde a un esfuerzo teórico y conceptual inicial para justificar tal hipótesis, así caracterizar a la construcción de paz como un escenario propicio para superar el esquema positivista y generar nuevas epistemologías. De esta manera se busca proyectar estos resultados a la labor de formular nuevas estrategias en pedagogía y creación de CyT que sean pertinentes para la construcción de paz y la superación de las dinámicas de periferia, propiciadas por el actual modelo de desarrollo internacional. de nuestro continente. Se considera que estas nuevas estrategias de pedagogía y de creación de conocimiento científico y tecnológico pasan también por la evaluación de los quehaceres propios de las y los científicos, y las y los ingenieros en contextos tan particulares como el caso colombiano. Este quehacer se puede inscribir en dos visiones, que tienden a consolidar las dinámicas de violencia, o a superarlas. La propuesta que aquí se formula busca plantear escenarios donde la ciencia y la ingeniería, revisen y re-evalúen, conceptos y aspectos epistemológicos, en función de consolidar la paz en Colombia, y crear oportunidades de progreso del sur global enmarcado en aspectos que deben ir más allá de la concepción usual de desarrollo.

El texto está organizado de la siguiente manera: en la sección 2, se analiza el surgimiento del conflicto armado en Colombia. Este análisis se debe al gran esfuerzo que hizo la Comisión Histórica del Conflicto y sus Víctimas (CHCV). Se realizan de manera adicional, algunos esbozos sobre la situación de la CyT enmarcada en el surgimiento y desarrollo de este conflicto. En la sección 3, se propone de una manera general una simbiosis entre las energías renovables y alternativas (ERA), la agroecología y la etnobiología, como base fundamental para nuestra propuesta central. En la sección 4 se caracteriza nuestra propuesta sobre la definición de la construcción de paz en Colombia como escenario ideal para la construcción de nuevas pedagogías y epistemologías para el desarrollo del conocimiento científico y tecnológico en Nuestra América. La sección 5 es dedicada a las conclusiones y posibles extensiones de este texto.

\section{SURGIMIENTO DEL CONFLICTO ARMADO EN COLOMBIA, EN CLAVE DE CYT.}

El inicio del desarrollo del proceso de Paz entre la insurgencia de las FARC-EP y el gobierno colombiano, estuvo direccionado por preguntas orientadoras que hacían referencia al origen del conflicto armado en Colombia. Tal tarea, estuvo a cargo de la CHCV. En esta sección destacamos los elementos más importantes del texto emanado de la $\mathrm{CHCV}$, en clave de dos elementos fundamentales a saber: el origen rural del conflicto y el condicionamiento de las particularidades de la instauración del capitalismo en Colombia. Los componentes destacados los complementamos con elementos sobre el atraso científico y tecnológico, propiciado por la delimitación de políticas de CyT, que respondían a estas particularidades mencionadas de la instauración, que derivaba en el calco epistemológico y metodológico que no atendía (y actualmente no atiende) a las realidades contextuales.

En principio, el sistema de organización capitalista precisa de dos condiciones históricas iniciales. La primera es la existencia de trabajo libre que pueda ser intercambiado por dinero bajo la forma salarial. La segunda, es la separación de los titulares de ese trabajo de las condiciones objetivas de su realización; en otras palabras, la separación de medios de producción y objeto del trabajo. Uno de los obstáculos que encuentra la instauración de este sistema de organización son las formas sociales que ligan al trabajador a la tierra bajo cualquier modalidad jurídica de apropiación 
(Moncayo Cruz, 2015). La disolución de tales vínculos con la tierra, se hace entonces necesaria para la producción en el esquema capitalista. Se debe dar fin a la unión, fusión, vínculo o amalgama entre la humanidad y la naturaleza como su cuerpo no orgánico, en un proceso que "presenta una modalidad diversa en cada país, y en cada uno de ellos recorre las diferentes fases en distinta gradación, y en épocas históricas diversas" (Marx, 2014, p. 804).

Las formas de propiedad que constituyen un obstáculo a la instauración del capitalismo, encuentran dos rutas clásicas de transformación y adecuación, a saber: la vía inglesa donde se crea proletariado expulsando violentamente a los campesinos de las tierras donde trabajan; mediante expropiación, apoyo de la ley o arrasamiento drástico y brutal. El otro camino es el reformista (adoptado por Francia y Rusia) donde se buscaba transformar a los campesinos en pequeños o medianos propietarios, para que se conviertan en los interlocutores del capital o los agentes libres de la relación salarial. Ambas rutas operan con el objetivo de liberar la fuerza de trabajo. Sin embargo, no logran consolidar por ellas mismas el hecho de que la producción asentada sobre el medio agrario se convierta en producción capitalista. Este es otro proceso conocido como la introducción del capitalismo en la agricultura (Moncayo Cruz y Rojas, 1979). La Colombia de principios del siglo XX exigió una gran demanda de fuerza de trabajo debido a la expansión cafetera, la construcción de una infraestructura vial y de puertos, y la consolidación de una incipiente industria manufacturera. Tales procesos apremiaban la liberación de la fuerza laboral y la libertad de cultivo en las parcelas de subsistencia.

Las reivindicaciones de las clases subalternas comienzan a ser parte del panorama nacional. Tales reivindicaciones superaban con creces los objetivos de la instauración del capitalismo. Ante la insuficiencia de los aparatos legales y jurídicos consolidados en el seno de los procesos de la clase dominante, se procede a lo esperado: la expulsión de los campesinos que reclamaban salarios similares a los urbanos, o que pretendían reivindicar la titularidad de los predios. Los grupos de campesinos expulsados migraron a los centros urbanos o tomaron el camino de la colonización expandiendo la frontera agrícola.

La expansión de la frontera agrícola, producto de estos procesos de represión, junto con el establecimiento del latifundio como empresa capitalista (que se explicará más adelante), fue uno de los principales componentes del conflicto armado y del atraso científico y tecnológico del país. Esta expansión consolidaría el escenario perfecto para el crecimiento exponencial de los cultivos de uso ilícito y significaría un desarrollo rural desordenado y ajeno a todo tipo de investigación o avance científico y tecnológico, ligado al progreso agropecuario (Del Valle Rivera et al., 2016). La reforma a la ley 74 de 1926 impulsada por Olaya Herrera o aquella promovida por Lleras Restrepo en 1934 (ambos dirigentes liberales) intentaron dar soluciones a esta situación que en realidad no fructificaron (Moncayo Cruz, 1975).

Después de estos intentos, en plena república liberal se llega a la ley 200 de 1936. Bajo el marco de esta ley se pretendía presionar la explotación económica de los predios incultos bajo la amenaza de la extinción del dominio con un plazo de 10 años. Se notaba una clara índole de protección de la gran propiedad para incentivar su transformación capitalista, acogiendo a su vez la ruta inglesa. La ley desalentaba entonces las pretensiones de los campesinos por la tierra, originando una ampliación de la frontera agrícola mediante la colonización. Finalmente, la ley 100 de 1944, (promulgada en el segundo periodo de López Pumarejo) alentaba la tendencia de la promoción de la gran propiedad agraria como base del desarrollo capitalista en el campo. La ruta elegida por la 
clase dominante colombiana "impulsaba la transformación de los latifundios en grandes empresas capitalistas, aceptando que, durante el plazo otorgado para su explotación eficiente, puedan utilizarse las formas pre o no capitalistas, reteniendo gradualmente el proceso de expulsión y garantizando la oferta agrícola demandada" (Moncayo Cruz, 2015, p. 42).

Hubo respuestas ante este ataque de la clase dominante, las más representativas fueron: Las movilizaciones indígenas contra la Casa Arana en el Putumayo; las movilizaciones de las comunidades originarias del Catatumbo expulsadas violentamente por las explotaciones petroleras; las típicamente agrarias en el Sumapaz; las de expresión bipartidista; las provocadas por el retorno campesino como efecto de la crisis de 1929 y con ello la aparición de actores organizados como la UNIR, el PAN y el Partido Comunista.

Si bien a principios del siglo XX se tenía una Comisión Científica Nacional (1917), tiempo después, junto a la reestructuración de las universidades, la creación de la Universidad Nacional en Bogotá y la escuela de minas en Medellín, la organización científica moderna en el país encuentra sus primeros pasos en la conformación de sociedades como el Instituto Nacional de Higiene (1924), la Federación Nacional de Cafeteros y sus granjas experimentales (1927), el Herbario Nacional (1931), el Instituto Nacional de Cancerología (1934), la Academia de Ciencias Exactas, Físicas y Naturales (1933), el Instituto Geográfico (1934), la Escuela Normal Superior (1935), Cenicafé (1938), el Servicio Geológico Nacional (1940), el Instituto Etnológico Nacional (1941), entre otros (Plata, 2013).

Durante periodo de la segunda posguerra, a nivel global, se comienza evidenciar la creciente incorporación de cuestiones científicas y tecnológicas a las dinámicas del capital y las transformaciones económicas, geopolíticas y socioculturales del mundo moderno (Plata, 2013). En estos mismos años, en Colombia, se presencia un gran salto en el desarrollo capitalista, agudizando las expulsiones y expresiones violentas en el campo. Se incrementa el fenómeno de la violencia bipartidista, con especial énfasis en poblados rurales y apartados de los grandes centros urbanos. Esta violencia alcanza un punto neurálgico con el asesinato del líder liberal Jorge Eliécer Gaitán el 9 de abril de 1948. La situación desemboca en la dictadura militar de Gustavo Rojas Pinilla (19531957) que tiene una vocación de cambio consensuado por las clases dominantes de los dos partidos para interrumpir la amenaza que se percibe en el cambio de la naturaleza de la resistencia, enfrentar subversiones sociales tildadas de "comunistas", adelantar procesos de cooptación, impulsar la transformación agraria fortaleciendo la gran propiedad y avanzar en el modelo de desarrollo iniciado desde los años treinta.

Ante el agotamiento del proceso de la dictadura, se abre paso al pacto oligárquico del Frente Nacional (1958-1974). El cual cierra las formas normales de participación política. Debido a esto, hay un incremento de las manifestaciones subversivas que habían sido asumidas por en palabras de Moncayo (2015, p. 45): "las autodefensas campesinas, las guerrillas y los bandoleros liberales que, de alguna manera, eran movimientos continuadores de las luchas escenificadas en los años veinte y treinta del siglo $X X$, cuando el orden social y productivo capitalista iniciaba su implantación y producía sus primeros efectos en el mundo rural".

Los años 1960 perciben una oleada de promoción de la CyT para el desarrollo. La modernidad traza a la CyT como elemento obligado en su construcción. Los organismos multilaterales como la Organización para la cooperación y el Desarrollo Económico (OCDE) y la Organización de 
Naciones Unidas para la Educación, la Ciencia y la Cultura (Unesco) planteaban la necesidad de fomentar la CyT como factor de desarrollo económico y social. De esta manera, mediante el concepto de "transferencia de políticas" (Nupia, 2013), los organismos multilaterales establecían la consolidación de estos discursos en América Latina propiciando la creación de estructuras institucionales que gestionaran políticas de CyT en el marco de los requerimientos internacionales, dejando de lado el contexto local. Durante esta época, el avance científico y tecnológico recibe un impulso gracias a la concurrencia de factores internos y de cooperación técnica extranjera. Con el Frente Nacional, se evidencia una notoria extenuación del proceso de sustitución de importaciones de bienes de consumo, dando a lugar, el despegue dinámico de la producción nacional sustitutiva de bienes intermedios y bienes de capital, siempre enmarcada en la concentración monopólica.

La década de los 60 presenció esfuerzos gubernamentales respecto a la CyT con la creación de institutos públicos de investigación como el Instituto Colombiano Agropecuario (ICA), Instituto de los Recursos Naturales Renovables (Inderena), Instituto Nacional de Investigaciones GeológicoMineras (Ingeominas), Instituto de Investigaciones Tecnológicas (IIT), Instituto Nacional de Salud (INS), Instituto de Asuntos Nucleares (IAN), Instituto Nacional de Investigaciones Marinas (Invemar), entre otros. Sin embargo, estos institutos obedecían a necesidades particulares empresariales e industriales y no atendían la construcción propia de políticas públicas e institucionales respecto al avance científico y tecnológico como eje de progreso (Lucio-Arias et al, 2013).

El período del Frente Nacional también se ve determinado por fenómenos como la Revolución Cubana, la política estadounidense de la Alianza para el Progreso, el renacimiento de las luchas reivindicativas sindicales, la reconversión de la antigua guerrilla liberal en movimiento armado de connotación política y social expresada en el nacimiento de las Fuerzas Armadas Revolucionarias de Colombia (FARC), ligada al Partido Comunista, como consecuencia del ataque militar a la población rural de Marquetalia en mayo de 1964 y la aparición de otros procesos subversivos como lo fueron el Ejército de Liberación Nacional, al cual se vinculó el sacerdote Camilo Torres, y el Ejército Popular de Liberación en 1967. Se trata también de realizar una política de reforma social agraria que, debido a la tendencia histórica de consolidación y transformación capitalista de la gran propiedad tradicional, no tuvo éxito. Se da la elección irregular del presidente conservador Pastrana Borrero originando la conformación del grupo insurgente M-19. Se presenta una urbanización progresiva y caótica que arrojaba terribles problemas de desempleo. Se adopta la UPAC (Unidades de Poder Adquisitivo Constante) para posicionar al sector de la construcción como líder por su papel generador de empleo. Aparecen los primeros signos de economía ilegal ligada a los narcóticos, contrabando y corrupción. Se reducen también las barreras arancelarias y se postula una mayor exposición a la competencia internacional con el fin de revisar la estrategia sustitutiva de importaciones.

En el marco de las estrategias geopolíticas de la Alianza para el Progreso, la Guerra Fría, las tareas de la Organización de los Estados Americanos (OEA), la Unesco y la OCDE, para implementar en América Latina, el discurso del desarrollo económico en el nuevo orden mundial, y el papel de la CyT en la construcción de este, se crean los primeros grandes organismos de CyT en el subcontinente, antecedidos por el Conicet en Argentina (1958), el CNPQ en Brasil (1951) y el INIC en México (1950). Fruto de esta oleada latinoamericana, el 20 de noviembre de 1968 durante el gobierno de Carlos Lleras Restrepo, se crea el Fondo Colombiano de Investigaciones Científicas y Proyectos Especiales "Francisco José de Caldas" (Colciencias), adscrito al Ministerio de 
Educación Nacional y al Consejo Nacional de Ciencia y Tecnología (CNCyT). Colciencias nace como fondo nacional de financiación de investigación científica ligada a instituciones educativas. Sin embargo, la existencia paralela de otras unidades gubernamentales que también promocionaban la CyT, estaba propiciando una fragmentación institucional que dificultaba la coordinación de una política científica centralizada de mediano y largo plazo (Lucio-Arias et al., 2013).

Las décadas de los 70 y 80 contaron con una amplia gama de instituciones con distintas competencias que perseguían objetivos similares respecto a la promoción de CyT de manera paralela. Esta pluralidad contribuía en mayor medida a la falta de coordinación en el diseño y formulación de políticas científicas comunes y centralizadas. Hacia los finales de la década de los 80, frente a las presiones que se estaban ejerciendo dirigidas a la apertura económica, debido a su cercanía con el Instituto Colombiano de Comercio Exterior (Incomex) y la Junta del Acuerdo de Cartagena (encargada del desarrollo de la política tecnológica del Pacto Andino), Colciencias toma una posición activa en las discusiones sobre la promoción y creación de capacidades científicas y tecnológicas en el país (Lucio-Arias et al., 2013). También se logra la adscripción de Colciencias al Departamento Nacional de Planeación (DNP) y la institucionalización del Sistema Nacional de Ciencia y Tecnología (SNCyT).

A pesar de que estos avances se formulaban en función de elevar a la CyT como prioridad nacional, las relaciones de estas dos entidades con los ministerios e instituciones del sector productivo eran aún débiles. Para fortalecer estas relaciones el Consejo Nacional de Ciencia y Tecnología (CNCyT) validaba y aprobaba las políticas y prioridades en materia de CyT que formulaba Colciencias. Los Consejos de los Programas Nacionales de Ciencia y Tecnología (CPNCyT) cumplían la función de implementar dichas políticas, a seleccionar proyectos y su correspondiente recomendación de aprobación. Si bien en los CNCyT se tenía una amplia participación de ministros y viceministros, las operaciones de los Consejos se dificultaba cuando esta participación no era análoga en las discusiones sobre asignación de recursos (Salazar, 2013).

Los inicios de la década de los 90, se ven marcados por lo que se denominó la "apertura económica", que recogía los postulados neoliberales. Esta apertura arrasó con los pocos vestigios que aún quedaban de la estrategia de sustitución de importaciones, al abrir el mercado doméstico a la competencia internacional Puesto que el modelo de industrialización por sustitución de importaciones imperó en países periféricos, el estado se desliga totalmente de la necesidad de definir una política científica y tecnológica con el propósito de regular, orientar y fomentar las inversiones para la innovación (Del Valle Rivera, 2016). Se consolida entonces el auge de las políticas neoliberales y la Constitución de 1991 lejos de hacer una apertura democrática, introduce principios y reglas nuevas acordes con las transformaciones globales del capitalismo (De Zubiría, 2015; Moncayo, 2015), estrechamente ligadas a la redefinición de la misión del Estado para la instauración de bases firmes para el predominio de la economía de mercado y favorecer la internacionalización de la economía. Es así que sigue el fenómeno continental donde se presentan tasas de rentabilidad y crecimiento que expresan un desempeño deficiente de la economía capitalista mundial, lo cual podría explicar que la globalización neoliberal no es el producto del florecimiento del desarrollo científico y tecnológico (Ocampo Gaviria, 2007).

Desde la carta de 1991, Colombia se encuentra suscrita a un sistema mercantil en materia de derechos fundamentales como la salud y la educación. Se tiene que la educación ha sido sometida a principios de la lógica mercantil que son condición para la asignación de recursos estatales. Se 
fortalece una creciente monopolización privada de la calidad y excelencia en beneficio de los estratos socio-económicos altos. En lo que respecta a la educación superior, todo se orienta hacia la privatización y a transformaciones ajustadas a las exigencias del mercado laboral en detrimento de la excelencia y las verdaderas necesidades nacionales (Ocampo Gaviria, 2007).

En 1991 se crea el Sistema Nacional de Ciencia y Tecnología (SNCyT), que junto a la llamada Misión de los sabios, se impulsa a Colciencias, y el gobierno de turno promete que Colombia ha de tener políticas de CyT que contemplen el largo plazo, la sustentabilidad y que sean responsables. Sin embargo, nunca se tuvo un cumplimiento cabal de las promesas realizadas. El presupuesto en CyT no superó el 0,5\% del PIB. Siendo las Instituciones de Educación Superior, las que seguían promoviendo a gran escala la investigación científica y tecnológica, en consecuencia de la crisis de la educación superior, se tiene un avance incipiente de desarrollo científico y tecnológico. Se presenta una tendencia generalizada al calco metodológico de los países del norte y por ende, se tiene una ciencia e ingeniería que no responde a las particularidades del territorio nacional.

Como consecuencia de todo ello, al concluir la década de los noventa, la situación fue de recesión económica, se presentó una aguda crisis en el sector financiero, aumentó la deuda externa e interna, el sector industrial experimentó una verdadera debacle, se reforzó el poder de los monopolios y oligopolios, el desempleo alcanzó cifras nunca antes vistas; después de alcanzar un mínimo importante en 1994, en 1998 alcanza un alarmante 18\% y para el 2000 estaba en 20\% (Arango y Posada, 2001), las exportaciones tradicionales crecieron mínimamente frente a un aumento desmesurado de las importaciones; se reemplazó valor agregado interno por externo (Ocampo Gaviria, 2007; López, 2006; Jaramillo, 2002).

En 2009, Colciencias pasa a ser Departamento Administrativo de Ciencia, Tecnología e Innovación. Esto le daba un rango ministerial al ente, sin embargo, con carencia de competencias legislativas. Colciencias no ha tenido un nivel lo suficientemente alto y autónomo, como para discutir con los ministros o el DNP, las políticas o los presupuestos para la CyT. Su capacidad como entidad rectora de la CyT ha sido realmente mermada. Los presupuestos así lo demuestran: Antes de 1990: 0.1\%; 1991, César Gaviria: 0.3\%; 1996, Ernesto Samper: 0.4\%; 2001, Álvaro Uribe: 0.37\%; 2006, Álvaro Uribe: 0.39\%; 2011, Juan Manuel Santos: 0.19\%; 2016, Juan Manuel Santos: 0.5\% (Pardo y Cotte, 2017; Maldonado, 2018).

Se puede evidenciar entonces cómo la élite colombiana ha sido insensible hacia el conocimiento, la educación y la investigación. Por la diversidad de tareas asignadas a Colciencias y su bajo presupuesto, es clara la ignorancia de esta élite sobre políticas de CyT. Es amplia y profunda. En Colombia ha primado el afán por la guerra, políticas de corto plazo y la entrega del país a los capitales internacionales. La ausencia de políticas de CyT se traduce inmediatamente en disminución de la calidad de vida de los ciudadanos, en atraso y dependencia. Es una realidad de facto que a mayores, más serias y consolidadas políticas de CyT, mayor ha de ser el desarrollo de la industria nacional, y con ello se tendrían más y mejores condiciones de vida con calidad y dignidad para la población (Maldonado, 2018).

Los avances logrados en materia de CyT se ubican en su mayoría en el resultado del trabajo específico de las universidades, públicas y privadas, de los grupos de investigación y de los propios investigadores, que en algunos casos tienen una visión desligada de la realidad nacional. Lo logrado 
no ha sido nunca el resultado de políticas nacionales de CyT. Este panorama tiene la tendencia de continuar en el futuro (Pardo y Cotte, 2017).

En palabras de Carlos Maldonado (2018):

Es lamentable la ausencia de políticas de ciencia y tecnología, es decir, de políticas a largo plazo de conocimiento e innovación (...) Que diversos gobiernos hayan sido indolentes hacia la ciencia y la tecnología no es sino la expresión eufemística para decir que el estado colombiano jamás ha sabido ni se ha interesado por la ciencia, la tecnología y la investigación. Aparentemente, para el Poder Ejecutivo, para el Congreso e incluso para el Sector Judicial, la ciencia es algo que carece de importancia. Cuando lo han intentado, los científicos jamás han sido plenamente escuchados. Un silencio peligroso separa a la comunidad académica y de investigación del poder político y económico. El poder no quiere escuchar a los pensadores e investigadores. Les teme según parece (p.1).

Ante este panorama, la formulación de un acuerdo de paz que asegurara la no repetición de la violencia en Colombia enfrentaba varios retos. Uno de ellos era la reformulación de políticas de ciencia y tecnología que consolidaran cambios en el modelo de desarrollo que habían elegido los distintos gobiernos. Esta reformulación tendría que pasar por el repensar el papel de la ciencia y la ingeniería colombiana. La forma en la que el conocimiento científico y tecnológico generado en el país estaba contribuyendo a la solución de las problemáticas en Colombia. Sin embargo, estas vías de solución tendrían que idearse en el marco de plantear nuevas formas de enseñar la ciencia y la tecnología, nuevas cuestiones en la formación de los científicos y los ingenieros, y nuevos paradigmas epistemológicos desligados de la concepción heredada de la ciencia y la tecnología que afianzaban la persistencia del conflicto en Colombia y la región, generado por el avance del proyecto neoliberal en Latinoamerica.

De esta manera, encontramos que el auge neoliberal se erige como una causa acumulativa del conflicto colombiano. En palabras de De Zubiría (2015):

La 'cosecha' que deja el 'diluvio neoliberal' se puede sintetizar en: una sociedad cada vez más desigual; una sociedad con cada vez más desempleo, subempleo y precariedad en el empleo; una sociedad en la que, cada vez, es mayor el número de pobres; una sociedad con deterioro de las condiciones de vida y con una movilidad social descendente; una sociedad en la que a los ciudadanos les son expropiados progresivamente sus derechos políticos y sociales por el mercado; una sociedad con cada vez mayores índices de violencia y criminalidad; una sociedad que no ofrece ningún futuro. (p.361)

\section{SIMBIOSIS ENTRE ERA, AGROECOLOGÍA Y ETNOBIOLOGÍA PARA LA PAZ}

Las crisis económicas inherentes al desarrollo del capitalismo y la instauración de tal sistema en el país, deja en entredicho la pertinencia de tal visión de la política y la economía, y lo que se desprende de estas esferas como el desarrollo social, humano, científico, tecnológico, filosófico, artístico, etc., para los países periféricos. Con esta apertura neoliberal, se identificaron de una manera más clara las debilidades de las fuerzas productivas en los países periféricos, así como sus efectos en la orientación de las actividades de investigación, en tanto que dichas actividades no se integran en un sistema de generación-utilización de conocimientos endógenos, pues por lo general se recurre a fuentes externas de conocimiento (Del Valle Rivera, 2016). 
En consonancia con entender el origen del conflicto armado en la ruralidad colombiana, consecuencia de la instauración del capitalismo en el país, en esta sección exploramos el primer punto de los Acuerdos de la Habana que trata la Reforma Rural Integral (RRI). Ante los retos anteriormente mencionados, sobre la necesidad de crear paradigmas contextuales frente a la formación de científicos e ingenieros, y la creación de nuevo saber científico y tecnológico, que promuevan cambios sustanciales en los esquemas de desarrollo actuales, se propone una simbiosis entre las Energías Renovables y Alternativas (ERA), la Agroecología y la Etnobiología para el desarrollo de esta RRI y como escenario primario de la construcción de nuevos paradigmas pedagógicos y epistemológicos de ciencia y tecnología en clave de construcción de una paz estable, duradera y con justicia social, que no sea simplemente nacional sino continental.

Esta simbiosis se piensa en articulación a ciertas líneas de acción que se trazan desde la ingeniería humanitaria (Reina-Rozo y León, 2017) y que se pueden plantear como escenario primario de una acción transformadora en el quehacer del científico y del ingeniero. Estas tres líneas propuestas (ERA, Agroecología y Etnobiología, y su unión) poseen elementos que son comunes con el fortalecimiento y construcción de ciencias e ingenierías con carácter contextual, crítico, transformador, robusto y disciplinado. Siguiendo la línea con la que cerramos la sección anterior, con la apertura neoliberal, en el aspecto agrario, los procesos han estado regidos por la agudización del conflicto armado y por la ampliación y profundización de las actividades ligadas a los cultivos de uso ilícito. La actividad vinculada a los grupos de investigación se vio totalmente desvinculada del sistema productivo y por ello no respondía de manera alguna a una estructura que podría asegurar una construcción económica basada en lo rural (Nupia, 2013; Plata, 2013).

Se observa que hay un sector que se desarrolla bajo el amparo de políticas de sustitución de importaciones de materias primas, aquel sector de sorgo, algodón, soya, maíz amarillo, cebada, arroz, industrias pecuarias intensivas (avicultura y porcicultura), cultivos de vocación exportadora (café, banano y flores). Las frutas, hortalizas, tubérculos y legumbres no cuentan con apoyo de políticas sectoriales y están volcadas al mercado interno; ligado a la economía campesina. La ganadería bovina se extiende en la frontera agropecuaria con el patrocinio del latifundio y de la concentración de la tenencia de tierra (Cueto Gómez, 2011).

En los textos de la CHCV (Moncayo, 2015) se logra poner de manifiesto una situación realmente preocupante. Los datos de varios informes permiten visibilizar el hecho de que en los departamentos con mayor concentración de la propiedad muestran las mayores cifras de desplazamiento forzado. Se ha producido un éxodo de la población rural en una proporción mayor al 10\% de la población total. Se evidencia también una coincidencia entre expansión de cultivos agro-industriales (en particular la palma africana y caña de azúcar, junto con la gran minería) con desplazamientos forzados de comunidades campesinas, cuyos epicentros se dan en Antioquia, Valle del Cauca, Chocó y en la costa del Pacífico. Se registra una estrecha relación con las áreas de mayores potenciales para el desarrollo de grandes proyectos agrícolas y mineros: Sur de la Guajira, Cesar, Urabá, Córdoba, Catatumbo, Sur del Bolívar, Buenaventura, Tumaco, Putumayo, Caquetá, Guaviare, Piedemonte del Meta y Arauca (Fajardo Montaña, 2015).

De tal manera que el estado en el cual estaba Colombia durante el desarrollo de los diálogos de la Habana, podría ser descrito por unas políticas agrarias que no salen de los aspectos ligados a infraestructura básica y vivienda, alianzas productivas y el incipiente desarrollo científico y 
tecnológico (Ocampo Gaviria, 2007; Jaramillo et al., 2013). También se centran en factores productivos y financieros focalizados en regiones donde se concentran las políticas de seguridad y de control territorial frente a las organizaciones armadas. Se evidencia en las actuales políticas agrarias una ausencia regente de la problemática de la tenencia de la tierra, el uso de ella, la atención a la producción campesina, la soberanía y seguridad alimentaria y energética, el cierre de la frontera agrícola y la reducción de la brecha entre lo urbano y lo rural, y el desarrollo científico y tecnológico para tales fines.

Es por esta razón, que los diálogos de la Habana, iniciaron con el tema de la tierra. Como resultado del acuerdo del primer punto, se estableció la RRI, formulando lo que llamaron "El marco hacia un nuevo campo colombiano". Este marco pone como objetivo fundamental, la creación de condiciones de bienestar para la población rural, asegurar las condiciones de trabajo, salud, educación y ocio. Se ponen de manifiesto tres ejes que son la transformación estructural del campo, es decir, la transformación de la realidad rural; la igualdad y enfoque de género; y el bienestar y buen vivir, que pasa por la erradicación de la pobreza. Se propone una convergencia entre la vida rural y urbana, respetando cuestiones que atañen al territorio, género, diversidad cultural y étnica (Mesa de Conversaciones, 2016).

El primer punto del acuerdo tiene un punto específico sobre la integralidad de la reforma. La integralidad asegura:

La productividad, mediante programas que acompañen el acceso efectivo a la tierra, con innovación, ciencia y tecnología, asistencia técnica, crédito, riego y comercialización y con otros medios de producción que permitan agregar valor. También asegura oportunidades de buen vivir que se derivan del acceso a bienes públicos como salud, vivienda, educación, infraestructura y conectividad y de medidas para garantizar una alimentación sana, adecuada y sostenible para toda la población. (Mesa de conversaciones, 2016, p.13).

De esta manera, se hace un llamado explícito a la implementación de innovación, ciencia y tecnología para asegurar la productividad de las comunidades rurales que han de surgir y/o consolidarse y asentarse con esta RRI. Puesto que la integralidad pasa por la asistencia técnica, crédito, sistemas de riego, alojamientos para semillas, comercialización, acceso a los bienes públicos como salud, educación y vivienda, consideramos que este es el escenario ideal para plantear un esquema de productividad sustentable, que se armonice con la naturaleza, y se construya y fortalezca con los saberes tradicionales, autóctonos y ancestrales.

Al plantear este esquema, se evidencia que el marco tradicional (positivista y hegemónico) de la ciencia y la tecnología, está totalmente agotado para la generación de avances científicos y tecnológicos basados en las características especiales geográficas, biológicas, meteorológicas, políticas, sociales, económicas, etc., que presenta nuestro territorio nacional. Se propone entonces que, los primeros pasos para la dignificación del campo colombiano, se den en el marco de la simbiosis mencionada. En primer lugar porque articula elementos centrales frente a cuestiones de avance en ingeniería tanto en lo técnico, teórico y práctico, como en lo referente a superar las concepciones heredadas y en segundo lugar, para llevar a cabo procesos de automatización, 
constante monitoreo, optimización y transformación de materia prima in $\mathrm{situ}^{2}$, de carácter sustentable, solidario, armónico con la naturaleza y las particularidades culturales y étnicas.

La sustentabilidad que se desprende de los estudios sobre las economías campesinas y familiares en Colombia, consiste en un enfoque ecológico, una comprensión sistémica y holística. Esta comprende y entiende la interdependencia entre sistemas naturales, sociales y económicos. Asegura que el crecimiento sostenido no es viable; comprende y utiliza la concepción de que hay límites. Tiene el principio fundamental de que el capital natural es insustituible, además propone una valorización, pero no monetiza los recursos naturales, no son cuantificables en dinero; no son mercadeables. Esta a favor de la co-evolución Y finalmente, parte del principio de precaución (Chaparro Africano, 2017).

La sustentabilidad anteriormente definida se complementa con la aplicación de las ERA en procesos que se enmarcan en el desarrollo de proyectos productivos con enfoque agro-ecológico. En este marco, se debe entablar un diálogo de saberes con las comunidades rurales, ya sean indígenas, afros y/o campesinos. Esto con el fin de aprovechar las potencialidades de las regiones y hacer infraestructuras mixtas que aprovechen no sólo la energía solar con módulos fotovoltaicos, sino la energía solar térmica, la biomasa y procesos termoquímicos, la energía eólica, la energía hidráulica, la energía de las mareas oceánicas y finalmente la energía geotérmica. Todo ello para generar nuevos paradigmas respecto al empleo eficiente y sustentable de la energía (Vega de Kuyper y Ramírez Morales, 2014), lejos del paradigma mercantil que ya se está imponiendo en las actividades propias de las energías renovables. Sostenemos que un proceso de industrialización en Colombia basado en lo rural y en una infraestructura energética e informática construida a partir de las ERA y del constante monitoreo y automatización, con elementos de hardware y software libre (Oliva Ramos, 2017), puede significar un cambio de paradigma para los países de la periferia en vía de trazar acciones en ciencia e ingeniería que se desliguen de los modelos del norte global.

La articulación de las técnicas de big data, machine learning, entre otras relacionadas con la inteligencia artificial (García Martínez et al., 2003; Caicedo Bravo y López Sotelo, 2009), con las actividades de producción agropecuaria con enfoque agroecológico, puede significar otra vía de avance en la formulación de paradigmas sustentables, que rescaten saberes ancestrales y promuevan pequeña y mediana industria rural. Un ejemplo de ello, son los proyectos que se están iniciando sus labores de ejecución en nuestros grupos de investigación adscritos a varias facultades de ingeniería de distintas instituciones de educación superior. En uno de estos, se están utilizando redes neuronales artificiales para investigar y optimizar la sustitución de fertilizantes químicos por microorganismos fijadores de nitrógeno y solubilizantes de fósforo para aumentar propiedades de crecimiento y nutritivas de pastos para ganadería. En otro, se pretenden hacer simulaciones predictivas, (usando sistemas de información geográfica, técnicas de machine learning y sensores en regiones) respecto a la relación entre agentes patógenos que afectan varios cultivos, propios de la economía familiar y campesina, y su expansión debida al cambio climático.

Un último proyecto, busca hacer modelos espacio-temporales de sistemas ERA basados en datos satelitales y sensores construidos por comunidades de excombatientes concentrados en los

2 Aspectos propios de la cuarta revolución industrial que se mencionarán más adelante y que son fuente de discusión en reformas en la enseñanza de la ciencia y la tecnología. 
Espacios Territoriales de Capacitación y Reincorporación (ETCR). Con lo cual se genere la tecnificación de proyectos productivos que están siendo desarrollados en estos lugares que tienen enfoque agroecológico, cooperativista y sustentable. Las caracterizaciones se realizan de manera participativa, tal que se generen elementos de ordenamiento con enfoque comunitario. La metodología que se usa para la construcción de estos ordenamientos es basada en diálogos de saberes y la Investigación Acción Participativa (IAP). Aspectos propios que se tratan en distintas líneas de investigación de grupos en ciencias e ingeniería, en articulación con otras disciplinas. Todo esto también en vía de construir nuevos modelos pedagógicos concernientes a la cogeneración y transferencia de conocimiento científico y tecnológico, como se establecerá más adelante.

Siguiendo esta línea, se pone de manifiesto el último componente de la simbiosis propuesta. La etnobiología es caracterizada por una diversidad de marcos teóricos y campos del conocimiento (Muniz, 2015). Se puede definir como el estudio del conocimiento biológico de ciertos grupos de plantas y animales, y sus interrelaciones, las cuales precisan ser entendidas mediante una perspectiva ecológica (Anderson, 2011). Este esquema nos ayuda a visualizar que los ecosistemas y los problemas ecológicos no pueden ser entendidos sin la influencia de la humanidad y de similar manera, los problemas culturales y sociales humanos no pueden ser entendidos sin considerar los ecosistemas y las interacciones ecológicas (Alburquerque, 2015). En este marco, tendemos que la etnobiología en contextos como el colombiano, busca rescatar los saberes ancestrales de las comunidades respecto a diferentes usos de elementos biológicos para distintas tareas (Ruíz, 2015). Esta forma de generación, adquisición y uso del conocimiento biológico, significa para nosotros una base para la elaboración de las nuevas pedagogías que articulen saber tecnológico y científico con las necesidades locales. La etnobiología, en sintonía con la agroecología y las ERA, brinda oportunidades para solucionar aspectos respecto a la optimización sustentable de los proyectos productivos comunitarios.

\section{PEDAGOGÍAS QUE EN EL CONTEXTO DE LA CUARTA REVOLUCIÓN INDUSTRIAL SON ÚTILES PARA LA CONSTRUCCIÓN DE PAZ}

Actualmente, el mundo se encuentra en constante cambio debido a la proliferación y auge de las tecnologías de la información y la comunicación en gran diversidad de aspectos de la vida diaria de las personas, tecnologías que producen una cantidad impensable de datos e información en cada instante (Meira, 2015), Cabe resaltar que el desarrollo industrial ha pasado por fases, en donde el ingenio humano ha sido aplicado para la solución de problemas y la generación de riqueza, desarrollo y mejora de la calidad de vida de la sociedad, al menos en teoría porque en la práctica no ha sido así. Estas fases inician con la invención de la máquina de vapor, continúan con el auge de las instalaciones eléctricas, posteriormente, con la sociedad de la información y, finalmente, el surgimiento de una nueva ruptura en los procesos, conocida como la cuarta revolución industrial (Zhou et al., 2016).

Este acelerado avance tecnológico, que se ha generado desde el surgimiento de la cuarta revolución industrial, ha sido posible gracias a la proliferación de una serie de tecnologías habilitantes. Dichas tecnologías pueden ser agrupadas en categorías como: tecnologías basadas en datos y computación, tecnologías basadas en la operación automática y tecnologías asociadas a la innovación y el 
emprendimiento (Maynard, 2015; Wanyama, 2018), que requieren de la combinación de conocimientos, herramientas y habilidades que de manera interdisciplinaria, relacionan los sistemas físicos, digitales y biológicos con el desarrollo sostenible y sustentable (Khan, 2017). De esta manera, la educación, como práctica de transmisión y apropiación de conocimiento, deba actualizarse y complementarse con una fuerte relación entre universidad, sociedad e industria (Frey y Sabbatino, 2018), no sólo para estar a la par del cambiante contexto tecnológico contemporáneo (Ciolacu et al., 2017), sino para el cumplimiento cabal de los Objetivos de Desarrollo Sostenible (ODS), donde los ingenieros juegan un papel cada vez más importante, no sólo a nivel técnico sino de manera integral, teniendo en cuenta que pueden, aportar sus habilidades y conocimientos para la construcción de una ingeniería que trabaje por el bienestar de las comunidades, que rompa las brechas sociales, la injusticia y la inequidad, que sea crítica, transformadora y solucionadora de los problemas que aquejan a la sociedad.

En este sentido, la ingeniería puede ser considerada como un proceso que mediante la interacción de conocimientos tecnológicos y científicos, junto con la habilidad, la práctica, la experiencia y la creatividad de quienes la practican, busca la manera de utilizar y desarrollar herramientas, métodos y aplicaciones que beneficien a la comunidad en la cual se encuentran inmersos, y que según el enfoque que se le da a la profesión puede ser dirigida a las élites o al servicio del pueblo (Osorio, 2004). Por tal motivo, es necesario conocer el contexto en el que se desenvuelve la práctica de la ingeniería y ser conscientes del impacto causado por las soluciones que se proponen para el bienestar de la sociedad. En la mayoría de los casos dichas soluciones generan nuevos problemas que antes no existían (Domingo y Segura, 2017).

No obstante, desde hace mucho tiempo, la formación del estudiante de ingeniería ha obviado tomar como fin último el aporte social de la profesión, para darle un sustento sólido a la formación profesional (Parra de Gallo, 2006). Sin embargo, el planteamiento de los Objetivos de Desarrollo Sostenible y el desarrollo de la cuarta revolución industrial, ofrecen la oportunidad de innovar en la educación (Garcia, Aguiar da Sila, Simas Carvalho, y Osorio de Andrade Guerra, 2017) con el fin de potenciar habilidades para la solución de problemas complejos (Motyl, Baronio, Uberti, Speranza, y Filippi, 2017; Phang, Anuar, Aziz, y Ahmad, 2016). Sin embargo, se hace necesario que desde el proceso educativo se haga una valoración crítica de las posibles consecuencias de esta innovación, con el fin de fortalecer otro tipo de relaciones sociales, basadas en dinámicas de construcción de paz, donde se fortalezca el trabajo colaborativo entre individuos y colectivos, que permitan modificar el modelo económico imperante y orientar el ejercicio de la ingeniería al servicio de las comunidades y la construcción de paz.

De esta manera, con el fin de adaptar las nuevas tecnologías al contexto educativo se han planteado e implementado diferentes estrategias pedagógicas que buscan innovar, desde una perspectiva emotiva, motivacional y práctica, el proceso de aprendizaje, usando herramientas didácticas que favorecen la formación integral de los educandos y transformándolos en sujetos activos en su proceso educativo y articulándolo con su proyecto de vida (Cabrol y Severin, 2010). Algunos de estos modelos vivenciales-experimentales de aprendizaje centrados en el estudiante son citados por Kolmos y de Graff, (2014), entre ellos se encuentran: el aprendizaje autónomo, el aprendizaje basado en casos, el aprendizaje experiencial, el aprendizaje de servicio, el aprendizaje de servicio basado en proyectos, el aprendizaje activo, la iniciativa CDIO: Concebir, Diseñar, Implementar, Operar, el aprendizaje basado en problemas y el aprendizaje basado en proyectos. Entre estos modelos, los que se han impuesto en las facultades de ingeniería como reacción a la educación 
convencional son el Aprendizaje de Servicio (Smith et al., 2005), el Aprendizaje basado en Problemas y/o Proyectos (ABP), conocido en la literatura como PBL por sus siglas en inglés y la iniciativa CDIO (Edström y Kolmos, 2012).

Adicionalmente, es importante resaltar que la construcción de paz es un proceso transversal en el cual todas las disciplinas se encuentran involucradas. Por este motivo, se hace necesario romper los esquemas y paradigmas de la educación tradicional, propiciando la creación de alternativas pedagógicas. Estas deben articular los diferentes saberes para la solución de problemas complejos mediante la utilización de una visión más holística que permita llegar a una mejor solución para la sociedad en general. Es ahí donde las diferentes estrategias pedagógicas toman una gran relevancia en el desarrollo de habilidades como la solución de problemas complejos, el pensamiento crítico, la creatividad, la iniciativa, la comunicación, la colaboración, la persistencia, la toma de decisiones, el liderazgo, la negociación y la flexibilidad cognitiva (ONU, 2015)

Por tanto, es necesario fomentar el trabajo en equipo, el uso de la didáctica para aprender y enseñar, la realización de procesos de crítica constructiva que re-alimenten el aprendizaje, la innovación en el aula dando la oportunidad para que los educandos también lo hagan, el ofrecimiento de autonomía para la toma de decisiones, el respeto a las diferentes posiciones y planteamientos de las personas, la comprensión de que el aprendizaje puede hacerse de los errores, el favorecimiento a la participación del estudiantado con preguntas y consultas, el entender que el proceso educativo también se ve influenciado por las emociones, y el fomentar la curiosidad, la adaptabilidad, la empatía y el liderazgo, entre otras muchas posibilidades (Saleh et al., 2017).

En este punto, cabe añadir que tecnologías de la información han propiciado el desarrollo de la sociedad, de manera que el conocimiento se divulga de una forma más sencilla, rápida y efectiva a través de diferentes canales de comunicación, permitiendo el acceso a un gran número de fuentes de conocimiento que se encuentran en plataformas de trabajo colaborativo y otros medios digitales, sin importar el lugar de procedencia de las fuentes, desde que se encuentren en un idioma comprensible para quien realiza la consulta. Sin embargo, el acceso a tanto conocimiento sin una guía o método, puede desembocar en la adquisición de conocimientos de forma dispersa e inclusive errónea, de manera que, si no se enfoca debidamente el acceso a la información hacia un objetivo claro con la finalidad de entender adecuadamente la información adquirida, los conocimientos no son interiorizados debidamente y por lo tanto no son asimilados por los estudiantes (Kriscautzky y Ferreiro, 2014).

Por ello, es fundamental que las comunidades busquen apropiar ese conocimiento en sus contextos locales con un enfoque orientado hacia la solución de problemas complejos, mediante el trabajo colaborativo. Esto, a partir de la interacción en red de diferentes comunidades para generar conocimiento, en donde los usuarios sean parte activa, De tal manera que la realización de proyectos en los que la utilización de avances tecnológicos distribuidos, con características de bajo costo, bajo consumo de energía, con capacidad de procesamiento local y comunicación inalámbrica, permita el empoderamiento de la comunidad y abona los primeros pasos hacia la soberanía tecnológica de la misma.

Muchas de éstas tecnologías se basan en la filosofía libre, la cual permite la democratización del conocimiento y fortalece las redes comunitarias. Dentro de ellas se encuentran tarjetas de desarrollo (hardware) como Arduino o Raspberry Pi y herramientas de software inspiradas en la libertad para 
crear, distribuir, modificar y usar las herramientas, tanto de software como de hardware según sus necesidades (Free Software Foundation, 2005; Open Source Initiative, 2005).

De esta manera, diversos usuarios alrededor del mundo pueden desarrollar prototipos o artefactos tecnológicos de acuerdo a sus necesidades personales o comunitarias, bien sea para uso recreativo o para la solución de problemas de su entorno, lo cual les facilita el desarrollo de habilidades que permiten empoderar y motivar a los individuos o colectivos al uso y desarrollo de software independiente de su profesión o carrera (Cataldi y Salgueiro, 2007). Para esto se hace un uso intensivo de estrategias para compartir, transferir y apropiar los conocimientos y desarrollos realizados, entre las cuales se encuentran foros, blogs, videos, repositorios y libros de acceso gratuito, que pueden incluir documentación de una gran diversidad de personas alrededor del mundo que han usado el hardware y software libre para resolver problemas, soluciones que dada las libertades de esta filosofía, pueden ser adaptadas para otros contextos de manera que beneficien a una comunidad en específico.

Gracias a las iniciativas que trabajan desde la construcción colectiva del conocimiento, antes que privatizar el acceso a la ciencia y la tecnología, ahora es posible diseñar, construir e implementar soluciones a diferentes problemas cotidianos mediante la utilización de dispositivos de bajo costo, fácil acceso y con capacidades de personalización. Estas pueden tener una cantidad casi infinita de aplicaciones para los diversos problemas que se plantean en el marco de los ODS. Es así como desde nuestros países latinoamericanos, se hace posible generar soluciones para problemas complejos desde el desarrollo de habilidades como la creatividad, la colaboración, el liderazgo, la comunicación y el pensamiento crítico, que, junto con algunas habilidades técnicas, ofrece a los países de nuestra región un compendio de posibilidades, con las que no se contaba antes, para empezar a construir una sociedad diferente.

En el caso puntual de Colombia, entendiendo que la ingeniería por sí misma no es ni buena ni mala, sino que cada individuo o colectivo tiene la posibilidad de elegir el uso y la aplicación que quiere darle a esta, y partiendo de una formación integral del estudiantado, que valore los diferentes saberes y maneras de acercarse al conocimiento, así como el fortalecimiento de las habilidades enunciadas anteriormente hacen que el contexto político de construcción de paz en el país se convierta en un escenario propicio para la construcción de alternativas pedagógicas, científicas y tecnológicas que permitan la dignificación de los diversos aspectos de la vida diaria, mediante la construcción de una disciplina que trabaje por el bienestar de las comunidades, que quiera romper las brechas sociales, la injusticia y la inequidad, que sea critica, transformadora y solucionadora de los problemas que aquejan a la sociedad, y que desde una perspectiva integral y holística incida en los procesos propios de la ingeniería, desde la formación, pasando por el ejercicio profesional y las labores investigativas, con el objetivo de promover y difundir nuevas maneras de hacer ingeniería, ciencia y tecnología para la construcción y la consolidación de la paz en el país.

\section{A MODO DE CONCLUSIÓN: HACIA LAS NUEVAS PEDAGOGÍAS Y EPISTEMOLOGÍAS EN CIENCIA Y TECNOLOGÍA}

En este escrito, se han sentado las primeras bases para intentar demostrar que la construcción de paz en Colombia (y el continente, por sus particularidades similares de violencia ocasionada por políticas de transferencia e intervencionismo) implica la exploración y desarrollo de nuevas 
pedagogías en ciencia y tecnología. Actualmente la implementación de los acuerdos de la Habana pone en tensión dos modos de concebir el desarrollo científico y tecnológico (y con ello la formación de futuros ingenieros y científicos). Una de estas visiones refuerza las dinámicas que han llevado a la exclusión, la inequidad y la persistencia de la pobreza y el conflicto. En un revés de lo planteado por los sectores sociales organizados, es esta visión la que se está imponiendo en la implementación de los acuerdos de paz (Ordoñez-Matamoros, 2018). La otra visión que implica las exploraciones y desarrollos innovadores ya mencionados involucra, de manera inexorable, el hecho de tomar distancia del esquema positivista que ha dominado las dinámicas de generación de conocimientos en estas áreas.

Este esquema epistemológico, ha cimentado el paradigma del desarrollo (más explícitamente del desarrollo sostenible) y con ello fortalecido las dinámicas centro-periferia, propiciando así, entre otros aspectos, la subordinación científica y tecnológica de los países del mal llamado "tercer mundo". Esto ha generado una brecha entre la CyT pertinente y apropiada para las dinámicas y particularidades propias de cada territorio, y aquella que actualmente se origina en los países de la periferia para atender las necesidades del centro. Se propone entonces, que estas nuevas pedagogías permitan iniciar la tarea de modificar la relación existente entre el centro y la periferia. Proporcionando una visión más articulada con los problemas reales de la sociedad, que genere sinergia en las relaciones de transferencia y apropiación de nuevos conocimientos en la sociedad. A su vez, promueva un diálogo de saberes, y el saber ancestral, autóctono y tradicional, ocupe el lugar que merece; fortaleciendo también aspectos técnicos en las reformas curriculares que consoliden de una manera conceptual y profunda los cambios que se hacen precisos tanto la formación de científicos e ingenieros como en los esquemas epistemológicos actuales.

Este rescate de lo ancestral promovería la generación de tecnologías propias, que sean adaptables a las particularidades geográficas, biológicas, socio-ecológicas, meteorológicas, etc., de los contextos locales y que posiblemente permitirían incrementos en la productividad compatibles con el crecimiento poblacional y con la apremiante necesidad de reducir la pobreza. La generación de nuevas pedagogías en $\mathrm{CyT}$, tendría que sentar bases para nuevos esquemas epistemológicos en $\mathrm{CyT}$, con el fin de que estos conocimientos, nacidos de estos nuevos esquemas, generen estrategias que permitan disfrutar a las generaciones venideras una mejora en sus niveles de vida, sin comprometer los recursos naturales, utilizándolos de forma eficiente (Urquidi, 1962). Desarrollando una CyT que proteja la naturaleza, transitando hacia otros métodos de fabricación, yendo hacia una producción más limpia, que implique el uso de tecnologías y esquemas productivos que disminuyan las desigualdades sociales. Pues como bien lo decía Alejandro Nadal (1977):

El quehacer científico y la utilización de conocimientos están condicionados de manera fundamental por la estructura económica y social en la que se desarrollan. La investigación científica (y la utilización de conocimientos) constituyen hechos sociales y, por tanto, su objeto, su metodología y sus fines están sometidos a la influencia del modo particular en que se organiza la producción, al grado de desarrollo de las fuerzas productivas y a las ideas mediante las cuales una sociedad mantiene su explicación del universo y justifica la racionalidad de su sistema socio-económico y político. (p.30)

Este objetivo que hemos de proponer, de establecer metodologías para el surgimiento de nuevas epistemologías emancipadoras en clave de nueva educación y de creación endémica de CyT, 
además de partir de la toma de distancia del esquema positivista (como lo mencionamos anteriormente), precisa de iniciar el trayecto con unas bases epistemológicas y formas de acercarse al conocimiento sólidas que han surgido en la periferia. Hacemos el llamado a emprender este camino desde, por ejemplo, análisis fuera del esquema capitalista-positivista (p.ej. marxistas, anarquistas o pos-capitalistas); de investigación acción participativa de la creación de CyT, formas de aproximación al conocimiento distintas como las estructuras filosóficas orientales o aquellas de las comunidades aborígenes africanas e indígenas de América.

Retomar las discusiones de los análisis latinoamericanos en CyT, desde las distintas aristas como lo son las teorías del poder, las económicas y aquellas más técnicas y filosóficas. ¿Existirán algunas otras "insurgencias" epistemológicas para ello? Estamos en búsqueda de ellas y lo mencionado sigue bajo investigación por parte los grupos suscritos enfocándose en aspectos teóricos, conceptuales, técnicos y epistemológicos frente a la inserción de la ciencia y la ingeniería en esquemas multidisciplinarios que promuevan cambios profundos en las estructuras. Por otro lado, comprendemos que si bien es claro que la sociedad civil en su conjunto tiene que ser garante de la implementación de los acuerdos, los científicos, intelectuales, ingenieros y demás miembros de la comunidad académica e intelectual colombiana, tienen que posicionarse en el frente junto a las organizaciones sociales para que con el pos-acuerdo se salden deudas históricas y lleven a Colombia a un momento diferente de su historia.

Asimismo, comprendiendo al Estado como elemento in-disociable del capitalismo, hay que tener la claridad de, como lo mencionaba García Linera (2010, p. 1), "cualquier alternativa postcapitalista es imposible a nivel local, es imposible a nivel estatal, una alternativa postcapitalista, que supere las contradicciones de la sociedad moderna, de la injusta redistribución de la riqueza, de la destrucción de la naturaleza, de la destrucción del ser humano, tiene que ser una obra común, universal, continental y planetaria". La ciencia y la ingeniería están llamadas a pensarse estas cuestiones en el marco de repensarse sus estructuras heredadas y cómo su transformación puede impulsar las transformaciones necesarias a nivel global.

Este artículo, donde se ha caracterizado la construcción de paz como un escenario propicio para cimentar nuevas epistemologías de $\mathrm{CyT}$, y con ello, nuevas pedagogías para generar conocimiento científico y tecnológico pertinente a las necesidades de la región, constituye el primero en una serie de trabajos. Los subsecuentes se plantean para ser la traslación a la práctica de las discusiones aquí planteadas y así comenzar con la construcción de las nuevas formas estipuladas. Al caracterizar la construcción de una paz efectiva de esta manera, se busca consolidar nuevos proyectos en el marco de la implementación de los acuerdos de paz que se basen en la simbiosis propuesta, el trabajo de investigación/acción con y para las comunidades, y que promuevan la creación de insumos para políticas públicas. Primeramente, para la sustentabilidad en el sector rural. En segundo lugar, para reformas estructurales en las mallas curriculares tanto en la educación básica y media, como en la superior. Finalmente para el establecimiento de nuevas formas epistemológicas de CyT en el marco de generación de planes de ordenamiento (rural y urbano) comunitarios con enfoque territorial, basados en inserción de elementos de la 4ta revolución industrial, las economías solidarias, horizontalidad, rescate de lo ancestral y armonización de la relación entre las comunidades y el resto de la naturaleza circundante. Estos temas están actualmente bajo investigación de los autores. 
Por esto, cerramos con el llamado de dos grandes colombianos que pensaron la Utopía como lo que verdaderamente es, una realidad alcanzable que nos convidan a construirla. El primero, Darío Botero Uribe (2005) quien decía:

La racionalidad es el patrón de pensamiento y acción aceptado en cada momento de la historia, que orienta la investigación y la acción en los distintos campos del conocimiento $y$ de la praxis (...) la razón permite comprender cómo piensan y actúan los seres humanos, dentro de qué parámetros, pero no explica cómo evolucionan en el pensamiento y la praxis (...) la Utopía es lo posible que no está contemplado (...) la Utopías es, entonces, desde un punto de vista, la distancia entre una racionalidad dominante, gastada y castrante, y una racionalidad previsible, que posibilita un pensamiento y una acción más ricos, más comprensivos o gratificantes. Esta distancia entre la racionalidad dominante y la racionalidad posible es la imaginación. Pero la Utopía no sólo es razón, la Utopía como la vida misma es también sensibilidad, en su más amplia acepción: sensualidad, goce, arte, creación, juego... La sensibilidad para modelar la cultura de un pueblo, aun cuando no tiene la misma significación de la racionalidad para el conocimiento y la praxis (p. 28).

Y Gabriel García Márquez:

Ante esta realidad sobrecogedora que a través de todo el tiempo humano debió de parecer una Utopía, los inventores de fábulas que todo lo creemos nos sentimos con el derecho de creer que todavía no es demasiado tarde para emprender la creación de la Utopía contraria. Una nueva y arrasadora Utopía de la vida, donde nadie pueda decidir por otros hasta la forma de morir, donde de veras sea cierto el amor y sea posible la felicidad, y donde las estirpes condenadas a cien años de soledad tengan por fin y para siempre una segunda oportunidad sobre la tierra (1982, p. 3).

\section{REFERENCIAS}

Alburquerque, U. P., Muniz, P., y Casas, A. (2015). Evolutionary Ethnobiology. Switzerland: Springer.

Anderson, E. (2011). Ethnobiology: overview of a growing field en: Anderson, E. N., Pearsall, D., Hunn, E., y Turner, N. (eds.) Ethnobiology. New Jersey, USA: Wiley-Blackwell.

Arango, L. E., y Posada, C. E. (2001). El Desempleo en Colombia. Borradores de Economía, Vol. 176, pp. 1-46.

Botero Uribe, D. (2005). El derecho a la Utopía. Bogotá, Colombia: Universidad Nacional de Colombia, Facultad de Derecho, Ciencias Políticas y Sociales.

Cabrol, M., y Severin, E. (2010). TICs en educación: una innovación disruptiva. En BID Aportes $\mathrm{N}^{\mathrm{o}} 2$ Disponible en Web: http://idbdocs.iadb.org/wsdocs/getdocument.aspx?docnum=35130690

Caicedo Bravo, E. F., y López Sotelo, J. A. (2009). Una aproximación práctica a las Redes Neuronales Artificiales. Cali, Colombia: Universidad del Valle.

Cataldi, Z., y Salgueiro, F. A. (2007). Software libre y código abierto en educación. Quaderns Digitals. Núm 48. Disponible en http://www.quadernsdigitals.net/datos/hemeroteca/r 1/nr 751/a 10208/10208.pdf 
Chaparro Africano, A. M. (2017). Sostenibilidad de la agricultura campesina, Cómo evaluarla y promoverla. Bogotá, Colombia: Corporación Universitaria Minuto de Dios, Ediciones de la U.

Ciolacu, M. et al. (2017). Education 4.0 for Tall Thin Engineer in a Data Driven Society. IEEE 23rd International Symposium for Design and Technology in Electronic Packaging (SIITME).

Cueto Gómez, I. (2011). Colonización y frontera agropecuaria en Colombia: De la gesta heroica de modernización, hasta el desarraigo forzado y la disminución de nuestra biodiversidad como producto de nuestra búsqueda del desarrollo. Revista punto de vista, Vol. 3, pp. 91-108.

De Sousa Santos, B. Decolonizar el saber, reinventar el poder. Santiago, Chile: LOM Ediciones.

Del Valle Rivera, M. (2016). Alejandro Nadal Egea: Del Análisis Académico a la Propuesta de Políticas. En: Ciencia, tecnología, innovación y desarrollo: El pensamiento latinoamericano. Ciudad de México, México: Fondo de Cultura Económica.

Del Valle Rivera, M. et al. (2016). Ciencia, tecnología, innovación y desarrollo: El pensamiento latinoamericano. Ciudad de México, México: Fondo de Cultura Económica.

De Zubiría Samper, S. (2015). Dimensiones políticas y culturales en el conflicto colombiano. Een: Conflicto Social y Rebelión Armada en Colombia, Ensayos Críticos. Bogotá, Colombia: Gentes del Común.

Díaz, E. (2010). Entre la tecnociencia y el deseo. La construcción de una epistemología ampliada -2a. ed.-. Buenos Aires, Argentina: Biblos.

Domingo, J., y Segura, J. (2017). Las humanidades en la ingeniería del siglo XXI. Actitudes y valores. Educaweb. Retrieved from http://www.upc.edu/latevaupc/lashumanidades-ingenieriasiglo-xxi-actitudes-y-valores/

Dos Santos, T. (2000). A Teoria da Dependência: Balanço e Perspectivas. Rio de Janeiro, Brasil: Civilização Brasileira.

Edström, K., y Kolmos, A. (2012). Comparing two approaches for engineering education development: PBL and CDIO. 8th International CDIO Conference, Brisbane, Australia.

Escobar, A. (1996). La invención del tercer mundo, construcción y deconstrucción del desarrollo. Caracas, Venezuela: Ministerio del Poder Popular para la Cultura.

Escobar, A. (2014). Sentipensar con la tierra. Medellín, Colombia: Ediciones Unaula.

Fajardo Montaña, D. (2015). Estudio sobre los orígenes del conflicto social armado, razones de su persistencia y sus efectos más profundos en la sociedad colombiana en Conflicto Social y Rebelión Armada en Colombia, Ensayos Críticos. Bogotá, Colombia: Gentes del Común.

Fals Borda, O. (1986). El problema de cómo investigar la sociedad para transformarla. Bogotá, Colombia: Tercer Mundo.

Ferrer, A. (2003). La Argentina y el orden mundial. Ciudad de México, México: Fondo de Cultura Económica.

Free Software Foundation. (2005). Definición del software libre. [ref. de 2005]. Disponible en Web: https://www.gnu.org/

Freire, P. (1987). Pedagogia do Oprimido, 17 ed. Rio de Janeiro, Brasil: Paz e Terra. 
Frey, M., y Sabbatino, A. (2018). The Role of the Private Sector in Global Sustainable Development: The UN 2030 Agenda. Corp. Responsib. Digit. Communities, pp. 187-204.

Garcia, J., Aguiar da Sila, S., Simas Carvalho, A., y Osorio de Andrade Guerra, J. B. S. (2017). Education for Sustainable Development and Its Role in the Promotion of the Sustainable Development Goals. In Curricula for Sustainability in Higher Education. Management and Industrial Engineering. https://doi.org/10.1007/978-3-319-56505-7

García Linera, A. (2010). La Construcción del Estado. Aporrea. Recuperado de https://www.aporrea.org/internacionales/a117621.html

García Marquez, G. (1982). La soledad en América Latina. Discurso de aceptación del Premio Nobel 1982. Disponible en https://www.nobelprize.org/prizes/literature/1982/marquez/25603gabriel-garcia-marquez-nobel-lecture-1982/

García Martínez, R. et al. (2003). Sistemas Inteligentes. Buenos Aires, Argentina: Nueva Librería. Iasi, M. L. (2007). Ensaios sobre consciência e emancipação. São Paulo, Brasil: Expressão Popular.

Jaramillo, C. F. (2002). Crisis y transformación de la agricultura colombiana 1990-2000. Bogotá, Colombia: Banco de la República.

Jaramillo, H., Villaveces, J., y Cantor, N. (2013). El pensamiento: Eje de legitimidad y gobernabilidad de Colciencias. En: Salazar, M. (ed.). Varios autores. (2013). Colciencias cuarenta años: entre la legitimidad, la normatividad y la práctica. Bogotá, Colombia: Observatorio de Ciencia y Tecnología (OCyT).

Khan, Z. R. (2017). Ethics Courses for IT students: Why is it crucial in the era of millennials and technology immersion?. 20th International Conference of Computer and Information Technology (ICCIT)

Kolmos, A., y De Graaff, E. (2014). Problem-Based and Project-Based Learning in Engineering Education: Merging Models en Johri, A., y Olds, B. M. (Eds.). Cambridge handbook of engineering education research (pp. 141-160). New York, USA: Cambridge University Press.

Kriscautzky, M., y Ferreiro, E. (2014). La confiabilidad de la información en Internet: criterios declarados y utilizados por jóvenes estudiantes mexicanos. Educaçao e Pesquisa, Vol. 40, núm. 4, pp. 913-934.

Leite Lopes, J. Ciência e Liberdade: Escritos sobre ciência e educação no Brasil. Rio de Janeiro, Brasil: Editora UFRJ/CBPF/MCT.

Lombardi, O. (2015). ¿Existe la flecha del tiempo?. Ilya Prigogine: entre la Ciencia y la Filosofia. Buenos Aires, Argentina: Logos.

López, E. (2006). La agricultura colombiana en el siglo XX. Bogotá, Colombia: Fondo de Cultura Económica.

Lucio-Arias, D., Salazar, M., y Durán-Sánchez, M. F. (2013). Entre la gobernabilidad y la gobernanza: Colciencias y los sistemas nacionales de ciencia y tecnología y de innovación. En: Salazar, M. (ed.). Varios autores. (2013). Colciencias cuarenta años: entre la legitimidad, la normatividad y la práctica. Bogotá, Colombia: Observatorio de Ciencia y Tecnología (OCyT). 
Maldonado, C. E. (2016). Complejidad de las ciencias sociales. Y de otras ciencias y disciplinas. Bogotá, Colombia: Ediciones Desde Abajo.

Maldonado, C. E. (2018). Colombia, un país sin políticas de ciencia y tecnología. Desde Abajo. Recuperado de: https:/www.desdeabajo.info/ediciones/item/33668-colombia-un-pais-sinpoliticas-de-ciencia-y-tecnologia.html

Martínez, F. (1998). Hacia una visión integral de la Ciencia y la Tecnología. Filosofía, Lógica y Problemas sociales de la Ciencia y la Tecnología. Universidad de Camagüey. Disponible en: http//:www.oie.es/salactsi/visión.htm

Marx, C. (2014). El Capital: Crítica de la Economía Política, Tomo I, Libro I. Nueva versión del Alemán por Wenceslao Roces. Ciudad de México, México: Fondo de Cultura Económica.

Maynard, A. D. (2015). Navigating the fourth industrial revolution. Nat. Nanotechnol., vol. 10, no. 12, pp. 1005-1006.

Meira, P. A. (2015). De los Objetivos de Desarrollo del Milenio a los Objetivos para el Desarrollo Sostenible: el rol socialmente controvertido de la educación ambiental. Educ. Soc. Rev. d'Intervenció Socioeducativa, vol. 61, pp. 58-73.

Mesa de Conversaciones. (2016). Acuerdo Final para la Terminación del Conflicto y la Construcción de una Paz Estable y Duradera. Bogotá, Colombia: Oficina del Alto Comisionado para la Paz.

Moncayo Cruz, V. M. (1975). La ley y el problema agrario. Ideología y Sociedad, No. 14-15.

Moncayo Cruz, V. M. (2015). Hacia la verdad del conflicto: Insurgencia guerrillera y orden social vigente en Conflicto Social y Rebelión Armada en Colombia, Ensayos Críticos. Bogotá, Colombia: Gentes del Común.

Moncayo Cruz, V. M., y Rojas, F. (1979). Producción campesina y capitalismo: Significación del programa de Desarrollo Rural Integrado, DRI. Bogotá, Colombia: Centro de Investigación y Educación Popular.

Motyl, B., Baronio, G., Uberti, S., Speranza, D., y Filippi, S. (2017). How will Change the Future Engineers' Skills in the Industry 4.0 Framework? A Questionnaire Survey. Procedia Manufacturing, 11(June), 1501-1509. https://doi.org/10.1016/j.promfg.2017.07.282

Muniz, P. et al. (2015). Ecological-Evolutionary Approaches to the Human-Environment Relationship: History and Concepts en Evolutionary Ethnobiology. Switzerland: Springer.

Nadal Egea, A. (1977). Instrumentos de política científica y tecnológica em México. Ciudad de México, México: Colegio de México.

Netto, J. P. Cotidiano: Conhecimento e Crítica. São Paulo, Brasil: Cortez Editora.

Nupia, C. M. (2013). Origen de la política científica y tecnológica en Colombia: Colciencias y su papel en la transferencia del modelo internacional de "política científica”. En: Salazar, M. (ed.). Varios autores. (2013). Colciencias cuarenta años: entre la legitimidad, la normatividad y la práctica. Bogotá, Colombia: Observatorio de Ciencia y Tecnología (OCyT).

Ocampo Gaviria, J. A. (ed.). (2007). Historia Económica de Colombia. Bogotá, Colombia: Editorial Planeta Colombiana. 
Ocampo López, J. (2009). El maestro Orlando Fals Borda sus ideas educativas y sociales para el cambio en la sociedad colombiana. Revista Historia de la Educación Latinoamericana, Vol. 12, pp. 13-41.

Oliva Ramos, R. (2017). Monitoreo, Control y Adquisición de Datos con Arduino y VisualBasic .Net. Ciudad de México, México: Alfaomega Grupo Editor.

ONU. (2015). Transformar nuestro mundo: la Agenda 2030 para el Desarrollo Sostenible. Asam. Gen. Septuagésimo período Ses. La Asam. Gen. las Nac. Unidas, del 11 al 18 septiembre del 2015 (resolución A/RES/70/1), vol. 16301, p. 40.

Open Source Initiative. (2005). Definición del software de código abierto. [ref. de 2005] Disponible en Web: https://opensource.org/osd

Ordoñez-Matamoros, G., Centeno, J. P., Arond, E., Jaime, A., y Arias, K. (2018). La paz y los retos de la política de ciencia, tecnología e innovación en Colombia en Soto, C. (ed.) Seguimiento y análisis de políticas públicas en Colombia. Bogotá, Colombia: Universidad Externado de Colombia.

Osorio M., C. (2004). Los Efectos de la Ingeniería en el Aspecto Humano. In XXIX Convención Panamericana de Ingeniería (p. 11). Retrieved from http://bit.ly/VcPree

Palma, H. A. (2008). Filosofia de las ciencias: Temas y problemas. Buenos Aires, Argentina: USAM EDITA de Universidad Nacional de General San Martín.

Pardo, C. I., y Cotte, A. (2017). Indicadores de ciencia y tecnología, Colombia 2017. Bogotá, Colombia: Observatorio Colombiano de Ciencia y Tecnología (OCyT).

Parra de Gallo, B. (2006). La formación humanística en el ingeniero. Cuadernos de La Facultad de Ingenieria E Informática, Vol 1, pp. 133-145.

Phang, F. A., Anuar, A. N., Aziz, A. A., y Ahmad, Y. (2016). Perception of Complex Engineering Problem Solving Among Engineerıng Educators. Engineering Education for a Smart Society. Advances in Intelligent Systems and Computing 215-224 https://doi.org/10.1007/978-3-31960937-9

Plata, J. J. (2013). Colciencias cuarenta años: Aprendizajes organizacionales y retos en las sociedades del conocimiento. En: Salazar, M. (ed.). Varios autores. (2013). Colciencias cuarenta años: entre la legitimidad, la normatividad y la práctica. Bogotá, Colombia: Observatorio de Ciencia y Tecnología (OCyT).

Possa, M. V. (2001). Maria da Conceição Tavares. Estud. av. Vol.15 no.43, São Paulo.

Reina-Rozo, J. D., y León Rojas, A. L. (2017). Ingeniería humanitaria desde/para el sur global en Belén Albornoz, M., Jiménez Becerra, J., y Rojas Álvarez, J. (eds.) Ingeniería, innovación y tecnología social. Bogotá, Colombia: Universidad Nacional de Colombia.

Ruíz, N. (2015). Conoce los avances en investigación de Etnbiología en Colombia. LAUD. Recuperado de http://laud.udistrital.edu.co/noticias/conoce-los-avances-en-investigaci\%C3\%B3nde-etnobiolog\%C3\%ADa-en-colombia

Salazar, M. (2013). Una mirada critica y reflexiva sobre el quehacer de Colciencias. En: Salazar, M. (ed.). Varios autores. (2013). Colciencias cuarenta años: entre la legitimidad, la normatividad y la práctica. Bogotá, Colombia: Observatorio de Ciencia y Tecnología (OCyT). 
Saleh, M. et al. (2017). Innovation in Education via Problem Based Learning from Complexity to Simplicity. 2017 Int. Conf. New Trends Comput. Sci., pp. 283-288.

Smith, K. A. et al. (2005). Pedagogies of engagement: Classroom-based practices. Journal of Engineering Education, vol. 94, núm 1, pp. 87-100.

Urquidi, V. (1962). Viabilidad económica de América Latina. Ciudad de México, México: Fondo de Cultura Económica.

Vega de Kuyper, J. C., y Ramírez Morales, S. (2014). Fuentes de Energía, renovables y no renovables, Aplicaciones. Ciudad de México, México: Alfaomega Grupo Editor.

Wanyama, T., Singh, I., Centea, D. (2018). A Practical Approach to Teaching Industry 4.0 Technologies. Lect. Notes Networks Syst. 22, vol. 22. (pág?)

Zhou, K., Liu, T., y Zhou, L. (2016). Industry 4.0: Towards future industrial opportunities and challenges. 2015 12th Int. Conf. Fuzzy Syst. Knowl. Discov. FSKD, pp. 2147-2152. 